\title{
Pengaruh Faktor Pendukung terhadap Perilaku Masyarakat dalam Pencegahan Penyakit Filariasis di Kota Semarang
}

\author{
Ariska Tri Hapsari*), Zahroh Shaluhiyah*), Antono Suryoputro*) \\ ${ }^{*}$ Fakultas Kesehatan Masyarakat Universitas Diponegoro \\ Korespondensi: ariskanabila01@gmail.com
}

\begin{abstract}
Background: Filariasis is chronic infectious disease due to filariasis worm infection which transmitted through mosquitoe bites. There were 241 districts as filariasis endemic districts in Indonesia. More than 50\% of the population in endemic areas are potential to contract with this disease. High prevalence of filariasis cases, can cause the increasing mortality cases if the disease did not treat it properly and prevent it early. There were 21 new cases found and three cases of them have died. This study aims to analyze the supporting factors influence to prevention behaviour of filariasis.

Method: This study is a quantitative study with a cross sectional design involved 178 respondents as total sampling. The people who live surrounding the filariasis sufferer $(\leq$ $100 m$ ) were recruited as a sample. Data collected using face to face interview by standard questionnaire. Data were analyzed using univariate, Chi-square test and multiple logistic regression.
\end{abstract}

Results: The results shows that the support of family, neighbors, and community leaders were not significant associated to the filariasis preventive behavior of respondents ( $P$ value $>0.05)$ while the support of health workers and the exposure of health promotion programs were significant associated the filariasis prevention behavior of the respondents. According to multivariate analysis, exposure on health promotion programs and supporting from health provider influenced the prevention behaviour of respondents with Odds Ratio 11.237 and $p$ value 0.023. The role of health providers in the prevention programs to the community was greatly important to improve knowledge, attitude, and people behaviour to prevent this disease. To reduce disease incidence is needed community empowerment program to improve community participation in preventing disease.

Keywords: filariaris, supporting factors, behaviour of preventing filariasis

\begin{abstract}
ABSTRAK
Latar Belakang: Filariasis adalah penyakit menular menahun karena penyebabnya adalah infeksi cacing filariasis yang ditularkan melalui nyamuk. Terdapat 241 kabupaten di Indonesia yang merupakan daerah endemis filariaris dan $50 \%$ penduduknya berpotensi tertular penyakit ini. Masih tingginya prevalensi kasus filariasis dibeberapa daerah dapat meningkatkan kematian. Kasus filariasis di Kota Semarang saat ini mengalami peningkatan dari tahun ke tahun. Pada tahun 2017 kasus filariasis terdapat sebanyak 21 kasus dan 3 diantaranya meninggal dunia. Penelitian ini bertujuan untuk menganalisis faktor pendukung perilaku masyarakat dalam mencegah penularan penyakit filariasis.

Metode: Penelitian ini merupakan penelitian kuantitatif dengan rancangan cross sectional dengan subjek penelitian sebanyak 178 orang. Sample dipilih secara total sampling (sampling jenuh) yaitu masyarakat yang tinggal $<100 \mathrm{~m} 2$ dari penderita. Data dikumpulkan melalui wawancara tatap muka dengan menggunakan kuesioner. Data kemudian dianalisis secara univariat, bivariate, multivarat dengan test Chi-square dan regresi logistic berganda.
\end{abstract}


Hasil: Hasil penelitian menunjukkan bahwa dukungan keluarga, tetangga dan tokoh masyarakat tidak berhubungan dengan perilaku pencegahan penyakit filarialis ( $\mathrm{P}$ value > 0.05), Sedangkan dukungan tenaga kesehatan dan akses atau keterpaparan terhadap promosi kesehatan tentang pencegahan filariasis berpengaruh terhadap perilaku pencegahan penyakit filariasis tersebut. Menurut hasil analisis multivariate, variabel keterpaparan program pencegahan merupakan faktor dominan yang berpengaruh terhadap perilaku pencegahan penyakit tersebut dengan Odds Ratio sebesar 11,237 dan p value 0,023. Peran tenaga kesehatan dalam keterpaparan terhadap program pencegahan penyakit filariasis kepada masyarakat sangat penting untuk merubah perilaku masyarakat dalam mencegah penyakit filariaris di daerah penelitian ini. Hal ini berupa perilaku dalam kebersihan lingkungan untuk menghilangkan tempat perindukan nyamuk filariasis. Diperlukan strategi upaya menurunkan prevalensi kejadian penyakit dengan melibatkan masyarakat melalui program pemberdayaan. Kata Kunci: filariaris, faktor pendukung, perilaku pencegahan, Semarang

\section{PENDAHULUAN}

Filariasis adalah penyakit menular yang disebabkan infeksi cacing filaria yang ditularkan melalui gigitan nyamuk. Infeksi sistemik yang disebabkan oleh cacing filaria dewasa yang hidup dalam kalenjar limfe dan darah manusia, menimbulkan pembengkakan pada tangan, kaki, glandula mammae, dan skrotum, serta dapat menimbulkan kecacatan seumur hidup apabila tidak mendapatkan pengobatan. ${ }^{(1)}$ Penyakit ini disebabkan oleh cacing dari kelompok nematode yaitu Wuchereria bancrofi, Brugia malayi, dan Brugia timor yang dapat menyebabkan produktifitas penderitanya menurun dan mengakibatkan kerugian akibat kehilangan jam kerja atau aktifitas sehari-hari yang disebabkan penyakit tersebut. ${ }^{(2)}$ Word Health Organization (WHO) sudah menetapkan Kesepakatan "The Global Goal of Elimination of Lymphatic Filariasis as a Public Health Problem by the Year 2020" yaitu program eliminasi yang dilaksanakan melalui pengobatan massal dan perawatan untuk mencegah kecacatan setahun sekali selama 5 tahun dan Indonesia sepakat untuk memberantas filariasis sebagai bagian dari eliminasi filariasis global. ${ }^{(3)}$ Data WHO menunjukkan bahwa 1,3 milyar penduduk dunia yang tinggal di 83 negara berisiko tertular filariasis dan $60 \%$ kasus berada di Asia Tenggara. ${ }^{(4)}$ Selain itu, sebanyak 947 juta jiwa di 54 negara atau $\pm 13 \%$ penduduk di seluruh dunia tinggal di daerah dengan potensi penularan filariasis, yang $80 \%$ diantaranya adalah Indonesia. Hal ini memerlukan upaya preventif untuk menghentikan penyebaran infeksi parasite tersebut agar tidak menyebar keseluruh masyarakat. ${ }^{(5)}$ Jumlah penderita filariasis di Kota Semarang sejak tahun 2011 hingga tahun 2016 terus meningkat. Sejak tahun 2011 telah ditemukan tiga (3) kasus baru filariasis, tiga (3) suspek di tahun 2012 yang telah 
ditetapkan sebagai kasus, enam (6) kasus ditemukan di tahun 2013, lima (5) kasus ditemukan di tahun 2014, enam (6) penderita filariasis ditemukan pada tahun 2015, dan lima (5) kasus filariasis di tahun 2016, sehingga secara kumulatif dari tahun 2011 sampai 2016 telah ditemukan 28 penderita filariasis di Kota Semarang, satu (1) penderita telah meninggal pada tahun 2013, dan satu penderita meninggal pada akhir tahun 2016. Penderita filariasis lakilaki berjumlah 9 orang dengan persentase $34,62 \%$ dan jumlah penderita filariasis perempuan sebanyak 17 orang dengan persentase sebesar $65,39 \%$ dan pada tahun 2017 menjadi 21 kasus, diantaranya tiga (3) meninggal dunia dua (2) warga yang menderita filariasis sudah pindah tempat tinggal. Sampai dengan saat ini belum dilaksanakan program pengendalian filariasis di Kota Semarang dikarenakan persentase microfilaria rate ( $m f$ rate) kota semarang $<1 \% .^{(6)}$ Kejadian filariasis berhubungan erat dengan beberapa faktor risiko, salah satu diantaranya ialah faktor perilaku. Perilaku masyarakat yang kurang menjaga kebersihan, seperti adanya air yang menggenang, air limbah dan parit dengan sampah yang berserakan disekitar rumah adalah salah satu habitat yang baik untuk perindukan dan tempat istirahat vektor/nyamuk spesies tertentu khususnya vector filariasis. ${ }^{(7)}$ Faktor lingkungan juga merupakan salah satu faktor yang mempengaruhi kepadatan vektor filariasis yaitu lingkungan fisik, lingkungan biologi yang buruk dan lingkungan sosial dan ekonomi yang kurang. Faktor lingkungan biologi meliputi tanaman air dan semaksemak. Keberadaan lingkungan biologi maupun fisik erat kaitannya dengan bionomik vektor filariasis, kepadatan vektor yang tinggi dan juga perilaku masyarakat dalam pemberantasan sarang nyamuk yang belum optimal. Tujuan dari penelitian ini untuk mengetahui faktorfaktor yang mempengaruhi perilaku Masyarakat terhadap pencegahan kejadian filariasis di Kota Semarang.

\section{METODE}

Penelitian ini merupakan penelitian penjelasan (explanatory research) dengan desain penelitian yang digunakan adalah desain potong lintang (cross sectional). Pengambilan sampel dilakukan dengan sampling Jenuh, dimana semua anggota populasi yang tinggal $\leq 100 \mathrm{M}$ dari rumah penderita filariasis digunakan sebagai sampel. Total sampel yang didapat adalah 178 orang kepala keluarga. Data dianalisis menggunakan univariate melalui frekwensi distribusi, bivariate dengan uji Ch-Square dan multivariate dengan logistic regressi ganda. ${ }^{(7)}$ Informed consent diberikan yang kemudian ditandatangani oleh responden untuk mengikuti penelitian ini. Ethical clearance didapatkan dari Komisi Etik 
Fakultas Kesehatan Masyarakat

Universitas Diponegoro.

\section{HASIL DAN PEMBAHASAN}

Tabel 1 menunjukkan karakteristik responden dengan presentase responden yang berumur $<50$ tahun lebih banyak yakni $(54,5 \%)$ dari pada usia $\geq 50$ tahun sebanyak 45,4\%). Mayoritas berjenis kelamin laki-laki lebih banyak yakni $(73,6 \%)$ dari pada berjenis kelamin Perempuan $(26,4 \%)$. Jenjang pendidikan menunjukkan pendidikan rendah (tidak tamat SD sampai dengan SMP) lebih tinggi yakni $(57,3 \%)$ dibanding pendidikan tinggi (SMA sampai dengan sarjana) yakni $(42,7 \%)$.

Tabel 1. Karakteristik Demografi Responden

\begin{tabular}{lrr}
\hline Karakteristik Responden & $\mathrm{N}$ & \multicolumn{2}{c}{$\%$} \\
\hline Umur & & \\
$<50$ & 97 & 54.5 \\
$\geq 50$ & 81 & 45.5 \\
\hline Jenis Kelamin & & \\
Laki-laki & 131 & 73.6 \\
Perempuan & 47 & 26.4 \\
\hline Pendidikan & & \\
$\begin{array}{l}\text { Rendah (Tidak Tamat SD } \\
\text { sampai dengan SMP) }\end{array}$ & 100 & 56.2 \\
$\begin{array}{l}\text { Tinggi (SMA sampai } \\
\text { dengan Sarjana) }\end{array}$ & 78 & 43.8 \\
\hline Jumlah & & \\
\hline
\end{tabular}

Tabel 2. Perilaku Pencegahan Filariasis, Dukungan Keluarga, Dukungan Tetangga, Dukungan Tokoh Masyarakat, Dukungan Tenaga Kesehatan, Ketersediaan Program Penyuluhan

\begin{tabular}{llrr}
\hline Variabel & Kategori & $\mathrm{N}$ & $\%$ \\
\hline Dependen & & & \\
Perilaku Pencegahan Filariasis & Buruk & 95 & 53.4 \\
& Baik & 83 & 46.6 \\
\hline Independen & & & \\
- Dukungan Keluarga & Tidak Mendukung & 64 & 36.0 \\
& Mendukung & 114 & 64.0 \\
- Dukungan Tetangga & Tidak Mendukung & 56 & 31.5 \\
& Mendukung & 122 & 68.5 \\
- Dukungan Tokoh Masyarakat & Tidak Mendukung & 58 & 32.6 \\
& Mendukung & 120 & 67.4 \\
- Dukungan Tenaga Kesehatan & Tidak Mendukung & 43 & 24.2 \\
& Mendukung & 135 & 75.8 \\
- Akses / terpapar Program & Tidak pernah & 166 & 93.3 \\
Penyuluhan & Pernah & 12 & 6.7 \\
\hline Total & & 178 & 100 \\
\hline
\end{tabular}


Tabel 3. Hubungan Dukungan Keluarga, Tetangga, Tokoh Masyarakat, Tenaga Kesehatan, Program Penyuluhan terhadap Perilaku Pencegahan Filariasis.

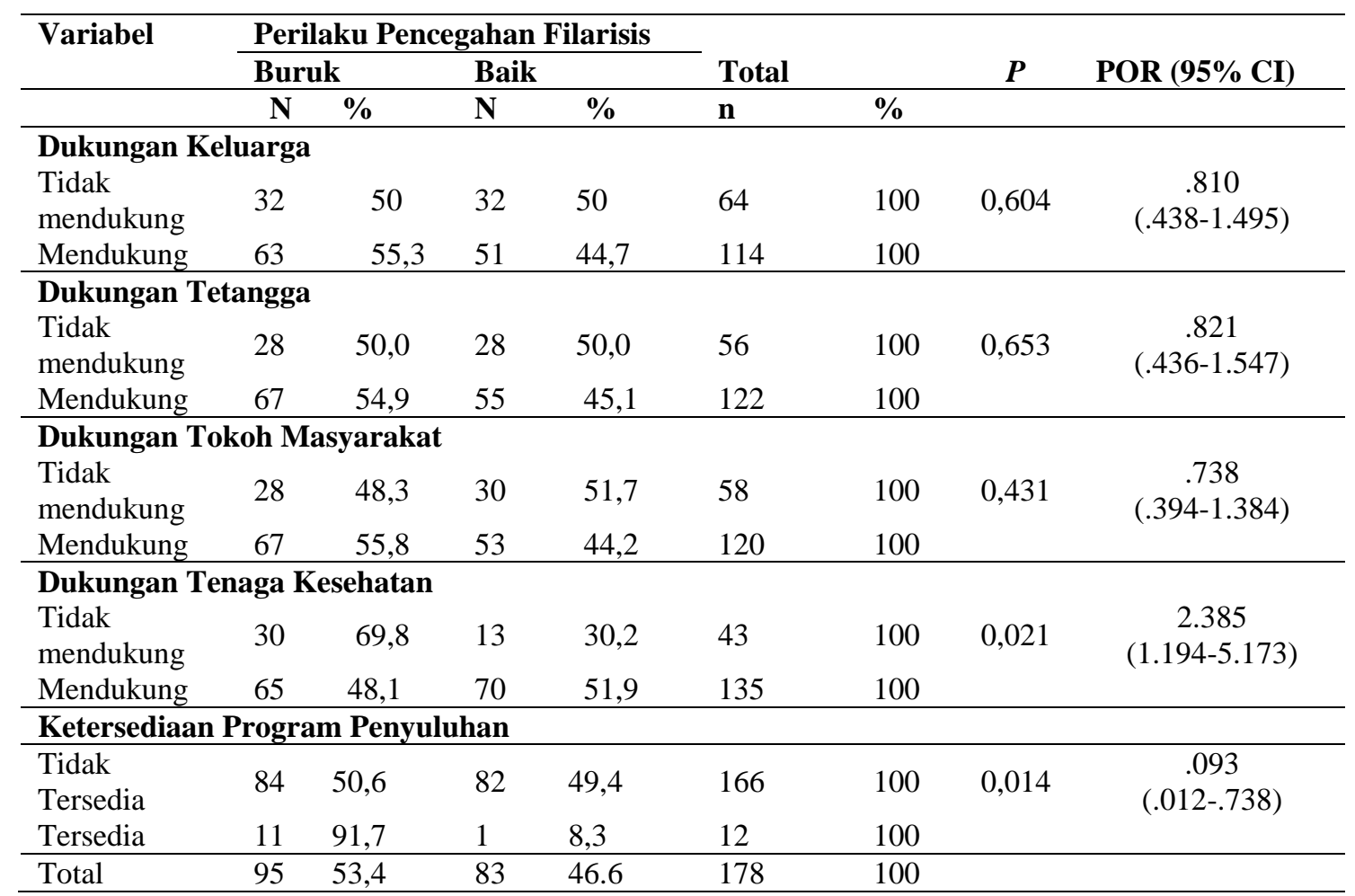

Tabel 2 menunjukkan bahwa perilaku responden dalam pencegahan filariasis lebih banyak yang berperilaku buruk $(53,4 \%)$ dibandingkan dengan yang berperilaku baik yaitu $(46,6 \%)$. Hal ini menunjukkan kesadaran masyarakat yang masih kurang dalam hal pencegahan filariasis. Sebetulnya dukungan dari keluarga, tetangga, tokoh masyarakat dan dukungan petugas dalam pencegahan filariasis seperti menjaga kebersihan lingkungan, pembersihan sarang nyamuk, semuanya lebih banyak yang mendukung dibanding dengan yang tidak mendukung. Tetapi pada prakteknya banyak responden yang berperilaku kurang atau buruk terhadap kebersihan lingkungan. Hal ini karena kebersihan lingkungan termasuk pencegahan air tergenang sebagai perindukan nyamuk aedes aegypti lebih difokuskan dibanding pencegahan penyakit filariasis sehingga masyarakat tidak mengerti dengan pencegahan penyakit filariasis. Penyuluhan yang sangat kurang tentang filariasis karena belum merupakan program puskesmas juga menjadikan masyarakat tidak paham tentang penyakit ini.

Tabel 3 menunjukkan bahwa presentase responden yang berperilaku pencegahan buruk lebih banyak terdapat pada responden yang memiliki dukungan keluarga terhadap pencegahan yakni $(55,3 \%)$ dibandingkan dengan responden 
yang tidak memiliki dukungan keluarga yakni $(50,0 \%)$. Untuk dukungan tetangga menunjukkan bahwa presentase responden yang berperilaku pencegahan buruk lebih banyak terdapat pada responden yang memiliki dukungan tetangga yakni $(54,9 \%)$ dibandingkan dengan responden yang tidak memiliki dukungan tetangga yaitu $(50,0 \%)$. Dukungan tokoh masyarakat menunjukkan bahwa presentase responden yang berperilaku pencegahan buruk lebih banyak pada responden yang mendapatkan dukungan tokoh masyarakat yakni $(55,8 \%)$ dibandingkan dengan responden yang tidak mendapat dukungan tokoh masyarakat yakni (48,3\%). Walaupun demikian dukungan keluarga, dukungan tetangga dan tokoh masyarakat tidak signifikan berhubungan dengan perilaku responden dalam pencegahan filariasis.

Dukungan tenaga kesehatan menunjukkan bahwa presentase responden yang berperilaku pencegahan buruk lebih banyak terdapat pada responden yang tidak memiliki dukungan tenaga kesehatan yakni (69,8\%) dibandingkan dengan responden yang memiliki dukungan tenaga kesehatan yakni $(48,1 \%)$ dan ketersediaan program penyuluhan menunjukkan bahwa presentase responden yang berperilaku pencegahan buruk lebih banyak pada responden yang terakses/terpapar program penyuluhan yakni $(91,7 \%)$ dibandingkan dengan responden yang tidak mengetahui ketersediaan program penyuluhan yakni $(50,6 \%)$. Hasil uji statistik dari semua variabel menunjukkan bahwa ada hubungan yang signifikan antara dukungan tenaga kesehatan dan ketersediaan program penyuluhan terhadap perilaku pencegahan filariasis.

\section{Dukungan Keluarga terhadap Perilaku Pencegahan Filariasis}

Hasil analisis bivariat menunjukkan bahwa presentase responden yang berperilaku pencegahan buruk lebih banyak terdapat pada responden yang memiliki dukungan keluarga yakni $(35,1 \%)$ dibandingkan dengan responden yang tidak memiliki dukungan keluarga yakni $(32,8 \%)$. Hasil uji statistik chisquare di peroleh nilai $p$ value $=0.604(\mathrm{p}>$ $0,05)$, hal ini berarti tidak ada hubungan yang signifikan antara dukungan keluarga dengan perilaku pencegahan kejadian filariasis. Dukungan keluarga (suami, orang tua, anak) ikut memberikan pengaruh positif terhadap perilaku pencegahan filariasis. Keluarga merupakan orang terdekat dalam mendukung kesehatan. Dukungan keluarga dapat mendatangkan rasa aman, rasa puas, rasa nyaman dan membuat orang yang bersangkutan merasa mendapatkan dukungan emosional yang akan mempengaruhi kesejahteraan manusia. ${ }^{(8)}$ Keluarga mempunyai efek yang sangat 
penting bagi kesehatan dan kesejahtraan berfungsi bersamaan, dengan adanya dukungan akan memberikan rasa kepercayaan diri untuk menghadapi masalah seperti sedang dalam keadaan sakit.

Menurut Friedman, terdapat hubungan yang kuat antara keluarga dan status kesehatan anggotanya dimana peran keluarga sangat penting bagi setiap aspek perawatan kesehatan anggota keluarga, mulai dari strategi-strategi pencegahan penyakit hingga fase rehabilitasi. Mengkaji dan memberikan perawatan kesehatan merupakan hal yang penting dalam membantu setiap anggota keluarga untuk mencapai suatu keadaan sehat hingga tingkat optimum. Menurut Moran menyatakan dukungan keluarga berpengaruh penting dalam pelaksanaan pengobatan berbagai jenis penyakit kronis sedangkan menurut Bosworth dukungan keluarga sangat berpengaruh terhadap kesehatan mental anggota keluarganya, atau lebih dikenal dengan dukungan sosial. Hal ini tidak terlepas dari kemampuan kepala keluarga yang dituntut mampu mengambil keputusan yang tepat untuk keluarganya, karena dukungan kepala keluarga dibutuhkan dalam partisipasi mencegah meluasnya penularan filariasis. Misalnya saja seperti dukungan suami atau istri yang selalu mengingatkan untuk selalu menjaga lingkungan rumah, anak yang mau membantu orang tua dalam membersihkan lingkungan rumah. Tetapi dalam hal ini dukungan keluarga seperti istri atau anak masih terkesan enggan dan tidak perduli untuk mengingatkan sesama anggota keluarga untuk menjaga kebersihan lingkungan rumah agar terhindar dari penyakit filariasis, walaupun mereka setuju untuk dilakukan pencegahan berbagai penyakit.

\section{Dukungan Tetangga terhadap Perilaku Pencegahan Filariasis}

Hasil analisis bivariate bahwa responden yang berperilaku pencegahan buruk lebih banyak terdapat pada responden yang memiliki dukungan tetangga yakni $(54,9 \%)$ dibandingkan dengan responden yang tidak memiliki dukungan tetangga yaitu $(50,0)$. Hasil uji statistik chi-square di peroleh nilai $p$ value $=0.653(\mathrm{p}>0,05)$, hal ini berarti tidak ada hubungan yang signifikan antara dukungan tetangga dengan perilaku pencegahan kejadian filariasis. Dukungan tetangga ikut memberikan pengaruh terhadap perilaku pencegahan filariasis, kebersamaan dalam melakukan kebersihan lingkungan dengan tetangga sering dilakukan bila ada perintah dari tokoh masyarakat terutama bila ada pemeriksaan jentik nyamuk demam berdarah. Tetapi bila tidak ada program dari puskesmas, maka masyarakat tidak peduli sesama untuk saling mengingatkan 
dan saling menjaga kebersihan lingkungan rumah agar tetap bersih dan sehat, seperti mengingatkan membersihkan pekarangan rumah, membersihkan drainase dari sampah-sampah, membersihkan barangbarang bekas yang ada di sekitar rumah sehingga dapat terhindar dari penyakit filariasis.

\section{Dukungan Tokoh Masyarakat terhadap Perilaku Pencegahan Filariasis}

Persentase responden yang berperilaku pencegahan buruk lebih banyak pada responden yang mendapatkan dukungan tokoh masyarakat yakni $(55,8 \%)$ dibandingkan dengan responden yang tidak mendapat dukungan tokoh masyarakat yakni (48,3\%). Hasil uji statistik chisquare di peroleh nilai $p$ value $=0.431(\mathrm{p}>$ $0,05)$, hal ini berarti tidak ada hubungan yang signifikan antara dukungan tokoh masyarakat dengan perilaku pencegahan kejadian filariasis. Hal ini sejalan dengan penelitian yang dilakukan oleh febri dkk, bahwa tidak ada hubungan antara dukungan tokoh masyarakat dengan perilaku pencegahaan penyakit filariasis $(p=0,716)$. Peran tokoh masyarakat untuk menjaga kebersihan lingkungan belum sepenuhnya terlaksana, dilihat dari kegiatan gotong royong belum terlaksana dengan rutin. Tokoh masyarakat merupakan salah satu faktor penguat tindakan seseorang. ${ }^{(9)}$ Tokoh masyarakat merupakan salah satu faktor penguat tindakan seseorang untuk memelihara dan melestarikan nilai-nilai kehidupan yang berdasarkan kegotongroyongan dan kekeluargaan serta untuk membantu meningkatkan kelancaran pelaksanaan tugas pemerintahan, pembangunan, kemasyarakatan di kelurahan dan meningkatkan peran serta masyarakat dalam pembangunan. Tetapi seringkali kegiatan tersebut hanya berjalan sesekali saja bila ada program yang diperintahkan oleh puskesmas.

\section{Dukungan Tenaga Kesehatan terhadap Perilaku Pencegahan Filariasis}

Responden yang berperilaku pencegahan buruk lebih banyak terdapat pada responden yang tidak memiliki dukungan tenaga kesehatan yakni $(69,8 \%)$ dibandingkan dengan responden yang memiliki dukungan tenaga kesehatan yakni (48,1\%). Hasil uji statistik chi-square di peroleh nilai $p$ value $=0.021(\mathrm{p}<0,05)$. Hal ini berarti ada hubungan yang signifikan antara dukungan tenaga kesehatan dengan perilaku pencegahan kejadian filariasis. Penelitian ini sejalan dengan peneliltian yang dilakukan oleh febri dan kawan-kawan, bahwa ada hubungan antara dukungan petugas kesehatan dengan perilaku pencegahaan penyakit filariasis $(p=0,001)$. Artinya perilaku hidup sehat yang dilakukan oleh 
masyarakat tidak hanya perlu pengetahuan dan dukungan fasilitas saja namun juga perlu adanya keteladanan dari petugas kesehatan. $^{(10)}$ Penelitian ini juga senada dengan penelitian yang dilakukan oleh imam dkk, bahwa dukungan petugas kesehatan dengan konsumsi obat kaki gajah didapatkan $p$ value 0,011 sehingga ada pengaruh dukungan petugas kesehatan terhadap konsumsi obat kaki gajah. Petugas kesehatan merupakan orang yang dipercaya oleh masyarakat dalam hal ini petugas kesehatan keberadaannya sangat diperlukan oleh masyarakat, ketika ada program yang harus dijalani masyarakat. Diharapkan Petugas kesehatan memberikan sosialisasi kepada masyarakat untuk meningkatkan pengetahuan dan keyakinan akan dampak akibat penyakit filariasis. $^{(11)}$

\section{Dukungan Ketersediaan Program Penyuluhan terhadap Perilaku Pencegahan Filariasis}

Hasil penelitian menunjukan bahwa presentase responden yang mengatakan tidak tersedianya progam penyuluhan lebih banyak yakni $(93,3 \%)$ dari pada responden yang mengatakan tersedianya progam penyuluhan yakni $(6,7 \%)$. Secara lebih rinci bahwa hasil penelitian menunjukan bahwa hanya $6,7 \%$ responden mengatakan tersedianya progam penyuluhan dan hamper seluruhnya $94,9 \%$ responden tidak pernah mendapatkan program penyuluhan pencegahan filariasis. Sebanyak 92,1\% responden tidak mendapatkan kunjungan dari petugas kesehatan untuk memberikan informasi tentang filariasi. Hasil uji statistik chisquare di peroleh nilai $p$ value $=0.014(\mathrm{p}<$ $0,05)$, hal ini berarti ada hubungan yang signifikan antara ketersediaan program penyuluhan dengan perilaku pencegahan kejadian filariasis. Dalam hal ini menurut responden, pihak kesehatan pernah datang kepada penderita filariasis yang ada didekat rumahnya untuk memberikan rujukan ke puskesmas dan diberikan pengobatan, tetapi pihak kesehatan tidak pernah memberikan penyuluhan ataupun kunjungan kesehatan mengenai filariasis kepada mereka. Tidak adanya ketersediaan penyuluhan mengenai filariasis dikarenakan tidak adanya program filariasis di Kota Semarang. Hal ini disebabkan angka mikrofilaria filariasis di Kota Semarang masih $<1 \%$. Menurut Kemenkes, jika angka mikrofilaria $>1 \%$ baru dikatakan daerah endemis dan diberikan program filariasis. Sementara itu semakin kurangnya informasi kesehatan yang diberikan kepada masyarakat tentang filariasis, kejadian filariasis di Kota Semarang tiap tahunnya mengalami peningkatan. Untuk itu diharapkan pihak terkait yaitu dinas kesehatan dan puskesmas dapat membuat kebijakan 
program kepada melalui gasurkes melakukan pemberdayaan masyarakat agar penyakit ini bias dicegah penyebarannya sedini mungkin dan kasus yang terjadi segera teratasi. Menurut penelitian santoso bahwa responden yang mendapat obat pada saat pembagian obat massal setelah kegiatan promosi kesehatan meningkat dari $80,3 \%$ menjadi 94,9\%, signifikan $(\mathrm{p}=0,002)$. Proporsi responden yang pernah minum obat pada saat pembagian obat massal setelah kegiatan promkes meningkat dari $70,1 \%$ menjadi $88,9 \%$. Selain itu hal ini juga sejalan dengan penelitian sarjono bahwa kegiatan penyebarluasan informasi tentang filariasis dapat meningkatkan pengetahuan, sikap dan perilaku masyarakat dalam mendukung kegiatan pencegahan filariasis. Menurut Arsunan bahwa pemberian penyuluhan kepada masyarakat di daerah endemis mengenai cara penularan dan cara pengendalian vektor nyamuk dapat mencegah untuk terkena penyakit filariasis dan dapat meningkatkan status kesehatan masyarakat. Kegiatan penyuluhan terhadap masyarakat perlu kerjasama dengan lintas sektor terkait, seperti lembaga swadaya masyarakat dan lembaga pemerintahan daerah. Penguatan sistem kesehatan dan membangun kerjasama lintas sektor merupakan hal penting dalam mengatasi masalah kesehatan masyarakat kesehatan yang tidak hanya menjadi tanggung jawab puskesmas atau dinas kesehatan saja dalam mengatasi penyakit filariasis terutama yang berhubungan dengan penggerakan masyarakat dalam kebersihan lingkungan. Menurut Notoadmodjo, adanya suatu tindakan seperti pendidikan kesehatan maupun promosi kesehatan akan menjadi stimulus / rangsangan dalam diri seseorang dalam bertindak. Kemudian dari stimulus tersebut akan terjadi proses yang memungkinkan seseorang untuk memberikan respon yang pada akhirnya melahirkan sikap tertutup yang dilanjutkan reaksi tingkah laku yang terbuka yaitu respon yang dapat menyikapi suatu tindakan baik tindakan negatif maupun tindakan positif. Promosi kesehatan mempengaruhi proses belajar, makin baik promosi kesehatan yang diberikan, makin mudah orang tersebut untuk menerima informasi, menyadari, menyikapi dan mempraktekannya. Promosi kesehatan, untuk mendapatkan informasi, dapat terjadi baik secara langsung dari orang lain maupun dari media massa. Semakin banyak informasi yang masuk semakin banyak pula pengetahuan yang didapat tentang kesehatan. Peningkatan pengetahuan tentang filariasis tidak mutlak diperoleh dari petugas kesehatan saja, tetapi pada pendidikan lain seperti TV, media social dan cetak atau kesenian masyarakat. 
Tabel 4. Faktor yang paling berpengaruh terhadap perilaku pencegahan filariasis

\begin{tabular}{lcccc}
\hline \multicolumn{1}{c}{ Variabel } & P Value & $\begin{array}{l}\text { POR 95\% CL for } \\
\text { EXP B }\end{array}$ & Lower & Upper \\
\hline $\begin{array}{l}\text { Dukungan tenaga } \\
\text { kesehatan }\end{array}$ & 0,013 & 1,391 & 0,186 & 0,823 \\
\hline $\begin{array}{l}\text { Ketersediaan program } \\
\text { penyuluhan }\end{array}$ & 0,023 & 11,237 & 1,404 & 89,916 \\
\hline
\end{tabular}

Faktor yang Paling Berpengaruh terhadap Perilaku Pencegahan Filariasis

Tabel 4 menunjukkan bahwa faktor yang paling berpengaruh terhadap perilaku pencegahan filariasis adalah ketersediaan program penyuluhan dengan Odd Ratio sebesar 11,237 (95\% CI: 1,404-89,916) dan Dukungan tenaga kesehatan dengan Odd Ratio sebesar 1,319 (95\% CI: 0,1860,823). Artinya bahwa masyarakat yang terakses dengan program penyuluhan tentang penyakit filariasis mempunyai kemungkinan untuk berperilaku baik dalam pencegahan filariasis sebesar sebelas $(11,2)$ kali dibanding yang tidak pernah akses penyuluhan filariasis. Sedangkan masyarakat yang mendapat dukungan petugas seperti dikunjungi petugas kesehatan dalam mengatasi penyakit filariasis, mempunyai kemungkinan berperilaku baik dalam pencegahan sebesar 1,3 kali disbanding dengan yang tidak pernah dikunjungi petugas kesehatan.

\section{SIMPULAN}

Faktor yang mempengaruhi masyarakat dalam melakukan pencegahan penyakit filariasis adalah keteraksesan atau keterpaparan dengan penyuluhan program pencegahan penyakit filariasis dan dukungan tenaga kesehatan berupa kunjungan tenaga kesehatan didaerah kasus filariasis sekaligus memberikan informasi kepada masyarakat sekitar. Kurangnya penyuluhan dari puskesmas dan perhatian petugas kesehatan terhadap kejadian penyakit filariasis menyebabkan masyarakat tidak melakukan pencegahan dan tidak peduli terhadap keberadaan penyakit tersebut di sekitar mereka. Peran tenaga kesehatan dalam promosi kesehatan kepada masyarakat sangat berpengaruh terhadap perilaku pencegahan penyakit filariaris di daerah penelitian ini. Untuk itu disarankan walaupun penyakit filariasis belum menjadi prioritas program tetapi pada daerah dengan peningkatan kasus, perlu upaya menurunkan prevalensi 
filariasis dengan memberikan penyuluhan pencegahan kepada masyarakat dan pemberdayaan masyarakat agar masyarakat sadar, mampu dan mau melakukan perilaku pencegahan,

\section{KEPUSTAKAAN}

1. Suryo S, Nurjazuli, Raharjo M. FaktorFaktor Yang Berhubungan Dengan Kejadian Filariasis Di Kecamatan Buaran Kabupaten Pekalongan. Jurnal Kesehatan Lingkungan Indonesia. 2017;16 (1), 22028.

2. Yanuarini C, Aisah S, Maryam. FaktorFaktor Yang Berhubungan Dengan Kejadian Filariasis Di Puskesmas Tirto 1 Kabupaten Pekalongan. Jurnal Keperawatan Fikkes. 2015;8(1):73-86

3. Zulkoni, A. Parasitologi Keperawatan Kesehatan Masyarakat Dan Teknik Lingkungan. Cetakan I. Yogyakarta: Nuha Medika; 2011.

4. Masrizal. Penyakit Filariasis. Jurnal Kesehatan Masyarakat Universitas Andalas. 2013; Vol 7 No 1.

5. World Health Organization. Lymphatic Filariasis: A Handbook Of Practical Entomology For National Lymphatic Filariasis Elimination Programmes. Department For International
Development Of The Government Of The United Kingdom Of Great Britain And Northern Ireland, Editor. Switzerland; 2013

6. Dinas Kesehatan Kota Semarang. Data Kasus Filariasis Semarang. Semarang; 2015.

7. Kementrian Kesehatan Republik Indonesia. Epidemiologi Filariasis Di Indonesia. Jakarta; 2010.

8. Nadirawati, Hubungan Dukungan Kepala Keluarga Dengan Partisipasi Keluarga Dalam Program Eliminasi (Minum Obat) Filariasis Di Majasetra Kabupaten Bandung. Jurnal Keperawatan Soedirman (The Soedirman Journal of Nursing), Volume 6, No.1, Maret 2011.

9. Saryono. Metodologi Penelitian Kesehatan Penuntun Praktis Bagi Pemula. Yogyakarta: Mitra Cendekia Offset; 2008.

10. Departemen Kesehatan Republik Indonesia. Peraturan Menteri Kesehatan Republik Indonesia Nomor 94 Tentang Penanggulangan Filariasis. 2014.

11. Dinas Kesehatan Jawa Tengah. Profil Kesehatan Provinsi Jawa Tengah. 2015. 